ISSN electrónico: 2172-9077

DOI: http://dx.doi.org/10.14201/fjc20161297116

\title{
LOS MILLENNLALS UNIVERSITARIOS Y SU INTERACCIÓN CON EL SOCIAL MOBILE
}

\section{College Millennials and their Interaction with Social Mobile Tools}

\author{
Dra. Sonia RUIZ BLANCO \\ Profesora Contratada Doctora. Universidad de Málaga, España \\ E-mail:sblanco@uma.es \\ (D) http://orcid.org/0000-0002-1342-7455
}
Dr. Francisco Javier RUIZ SAN MIGUEL
Profesor Titular. Universidad de Málaga, España
E-mail: sanmiguel@uma.es
(D) http://orcid.org/0000-0002-2210-0737

\author{
Dr. Fermín GALINDO ARRANZ \\ Profesor Titular. Universidad de Santiago de Compostela, España \\ E-mail: fermin.galindo@usc.es \\ (D) http://orcid.org/0000-0002-2764-2121
}

Fecha de recepción del artículo: 29/02/2016

Fecha de aceptación definitiva: 01/04/2016

\begin{abstract}
RESUMEN
Los docentes universitarios se enfrentan desde hace años al reto de enseñar a la denominada "generación Y" o "millennials" es decir, el grupo etario nacido entre 1980 y 2000 y que ha crecido con la existencia de Internet, lo que implica un acercamiento al conocimiento y al aprendizaje distinto de las generaciones anteriores. En el ámbito universitario, y sobre todo en los profesores de mayor experiencia, es común observar cierto nivel de preocupación ante la posibilidad de que los discentes lleguen con más conocimiento que el propio docente, sin embargo, los docentes que se han adaptado a estas nuevas tecnologías observan, con algo de asombro, cómo este grupo etario puede llegar a conocer muchas herramientas pero no así su uso adecuado, ni en el entorno personal ni el profesional. A lo largo de los últimos cinco años, hemos desarrollado una encuesta para cuantificar el número de herramientas relacionada con la Web 2.0 que usan los estudiantes, y su evolución a lo largo del tiempo, así como el uso que hacen de las mismas. Este artículo se centra en la relación de los discentes con respecto a dispositivos móviles y el uso de herramientas y servicios en los mismos.
\end{abstract}

Palabras clave: millennial; móvil; Smartphone; web 2.0; redes sociales; universidad. 


\begin{abstract}
In the past few years College professors has the challenge of teaching the so-called "Generation Y" or "Millennials", ie the age group born between 1980 and 2000 who raise with the existence of the Internet, which implies an approach to knowledge and learning different from previous generations. At college, especially more experienced professors are concerned over the possibility that learners knows these tools better than the professor himself, however, professors who have learned to use these new technologies have observed, surprisingly, as this age group can get to know many tools but not their proper use, in personal or professional environment. Over the past five years, we have conduced a survey about Web 2.0 tools used by learners, and their evolution over time as well as the use made of them.

This article focuses on the relationship between students and mobile devices and how they they use these tools and services.
\end{abstract}

Keywords: Millenial; Mobile; Smartphone; Web 2.0; Social networks; college.

\title{
1. INTRODUCCIÓN
}

Los "millennials" o "generación Y" son el grupo etario nacido entre 1980 y 2000 aproximadamente, cuya definición más sencilla y genérica sería la de un joven que no ha conocido un mundo sin Internet, pero tampoco sin ordenadores de mesa o portátiles, y por supuesto, un mundo sin teléfono móvil (Gardner y Davis, 2014, p. 16).

$\mathrm{Si}$ atendemos a las generaciones anteriores que también han conocido Internet, como son los "Baby Boomer" y la "Generación X", en el ámbito estadounidense vemos cómo sus personajes bandera estaban relacionados con la política: George W. Bush y Hillary Clinton en el primer caso, y Barack Obama con Sarah Palin en el segundo. Pero, en este nuevo grupo, los personajes destacados se alejan mucho de este ámbito, para adentrarse en las nuevas tecnologías y el espectáculo, como son Mark Zuckerberg (creador y fundador de Facebook) y Hillary Duff (actriz y cantante) (Howe y Strauss, 2007, p. 44).

Son muchos los autores que han estudiado esta generación, sin embargo resulta relevante mencionar algunas de las características que Howe y Strauss (2009) destacan de este grupo:

- Muy centrados en las calificaciones y el rendimiento: ciertamente vemos cómo las nuevas generaciones de estudiantes se preocupan más de sus calificaciones, sin embargo no se puede colegir una relación entre esta disposición y la tecnología. Cabe recordar que este mismo grupo es el que más duramente ha sufrido las consecuencias de la crisis económica actual, que concretamente en España ha supuesto que la última Encuesta de Población Activa (EPA de España 2015, 2016) nos muestre un 46,2 por ciento de paro entre la población menor de 25 años.

- Respetuosos de las normas e instituciones: no parece que sea aplicable a España, donde la situación económica actual ha facilitado el surgir de los movimientos sociales, empezando por el llamado 15-M y hasta la actualidad, donde hemos asistido al nacimiento de nuevos partidos políticos que han roto el bipartidismo imperante en nuestro país. Muchos de estos jóvenes se ven más identificados con estas nuevas formaciones políticas, con un discurso renovador e ilusionante.

- Exigiendo un entorno seguro y regulado: nuevamente se percibe la relación del entorno económico social actual y de inseguridad laboral que les hace demandar un futuro laboral con mejores condiciones y acorde a su formación y experiencia.

Sin embargo, desde la posición de los docentes universitarios, cada día se ve cómo estos jóvenes hacen un uso muy limitado, incluso en ocasiones desconocen, herramientas que les serían muy útiles en el desarrollo de sus habilidades académicas y profesionales. Resulta llamativo que autores como 
Mark Taylor (2005) se refieran a esta generación como "tecnoletrados"1, de modo que se sienten muy cómodos con la tecnología, pero al mismo tiempo son poco comprensivos con la falta de conocimiento tecnológico de otros, a los que podríamos llamar "tecnoiletrados" o "tecnoanalfabletos".

De ahí la inquietud que anima esta investigación, que se orienta a averiguar los límites de los conocimientos que poseen, del amplio abanico de oportunidades que les ofrece la Web 2.0, y qué uso hacen de todas estas herramientas, para así poder valorar su nivel de "tecnoalfabetización", tan importante hoy como lo fue la alfabetización en su momento. Dejando de lado cuestiones sociológicas como las connotaciones de clase o grupo social, se entiende que "analfabeta" es la persona que no sabe leer ni escribir, mientras que "analfabeto funcional" sería el individuo que habiendo adquirido las destrezas de leer y escribir, no es capaz de hacerlo en situaciones cotidianas como rellenar un formulario de empleo o entender las implicaciones legales de un contrato.

Hoy nos enfrentamos al mismo problema con la "tecnoalfabetización", de la que ya parece disfrutar gran parte de la población, incluídos nuestros "millennials", pero que se están mostrando como "tecnoanalfabetos funcionales" al hacer un uso muy limitado, y principalmente restringido al aspecto personal y lúdico, obviando las ventajas profesionales que podrían aprovechar de cara a su próxima inserción laboral.

Por tanto, educar en tecnologías de la información es educar para guiar hacia una "tecnoalfabetización funcional", con objeto de que en un futuro ya cercano los sujetos instruidos en estas materias puedan desenvolverse con soltura en el tecnologizado entorno que les espera. O como bien explican Monfort y Hurtado (2013): "Los estudiantes necesitan nuevos saberes operacionales y culturales con el fin de adquirir nuevos lenguajes que les den acceso a nuevas formas de trabajar y de prácticas cívicas y privadas en su vida cotidiana".

La Comunidad Europea se refiere a ello como "competencia digital” y la define así:

La competencia digital entraña el uso seguro y crítico de las tecnologías de la sociedad de la información (TSI) para el trabajo, el ocio y la comunicación. Se sustenta en las competencias básicas en materia de TIC: el uso de ordenadores para obtener, evaluar, almacenar, producir, presentar e intercambiar información, y comunicarse y participar en redes de colaboración a través de Internet. (Comision Europea, 2007, p 7).

Y por tanto, más allá de la tecnoanalfabetización básica, para adquir esta competencia digital requerimos conocimientos, capacidades y actitudes:

Tabla 1. Competencia digital

\begin{tabular}{ll}
\hline CONOCIMIENTOS & Conocer la naturaleza, función y oportunidades de las TIC en situaciones concretas de \\
& la vida privada, social y profesional. \\
& Conocer las principales aplicaciones informáticas y los riesgos y oportunidades que \\
& ofrecen en todas las facetas de la vida y para la investigación y la innovación. \\
\hline CAPACIDADES & Buscar, obtener y tratar información. \\
& Utilizar la información de manera crítica y sistemática \\
& Evaluar la pertinencia de la información. \\
& Diferenciar entre información real y virtual. \\
\hline ACTITUDES & Adquirir una actitud crítica y reflexiva respecto a la información disponible. \\
& Usar con responsabilidad los medios. \\
& Desarrollar el interés por participar en comunidades y redes sociales, culturales y profe- \\
& sionales.
\end{tabular}

Fuente: (Cervera, Vidal, y Martínez, 2011, p. 162).

\footnotetext{
${ }^{1}$ Del inglés "technoliterate". 
Otro punto de reflexión que anima el presente estudio es el promocionado por las experiencias en el aula de los doctores Noguera, Grandío y Torrado (2011), quienes apuntan el poco sentido que tiene seguir, en las actuales circunstancias, con las rutinas docentes de hace diez años, en tanto en cuanto, el consumo de información por parte de los jóvenes es radicalmente distinto. Y, aunque el cambio de estas rutinas en un contexto amplio no es competencia de este artículo, no se puede obviar la oportunidad de transformar las aulas en "entornos de aprendizaje más atractivos, colaborativos y productivos” (Gallardo Echenique, Marqués Molías, y Bullen, 2014, p. 192).

Por tanto, conocer mejor cómo utilizan los jóvenes las TIC ayudará a implementar en el aula una serie de recursos que permitan una aproximación a ellos en su nuevo lenguaje. Y lo que es más importante, el desarrollo de competencias como las estrategias de colaboración, el trabajo en equipo y la gestión de proyectos (Arras Vota, Torres Gastelú, y García Valcárcel Muñoz Repiso, 2011, p. 5). En definitiva se trata de encontrar las herramientas adeucadas para una correcta "tecnoalabetización funcional":

El perfil del profesor universitario para el siglo XXI deberá centrar su atención en encontrar las mejores estrategias para aportar herramientas de alfabetización científica y tecnológica, que faciliten el desempeño de cada sujeto en una sociedad en transformación permanente. (Matilla et al., 2014).

Pero volviendo al estudio que aquí se presenta, y a la luz de todos estos interrogantes, señalar que la génesis del mismo arrancó en el curso académico 2011-12, cuando se realizó un sondeo a modo de prueba piloto entre un grupo de alumnos de Comunicación Audiovisual de la Facultad de Ciencias de la Comunicación de la Universidad de Málaga, para dilucidar si las sospechas tenían algún fundamento, pero al mismo tiempo para depurar las cuestiones que se debían plantear y que, lógicamente, con el transcurrir de los años, se han ido ajustando ligeramente, a medida que iban desapareciendo algunas herramientas y surgiendo otras nuevas, o simplemente porque con el transcurso del tiempo, los jóvenes, en su propio crecimiento digital, iban dejando de lado unas herramientas para irse adentrando en otras consideradas de algún modo más adultas; como ya apuntaba Tapscott (2009) citado por Druetta, Garay Cruz, López González, y Portillo Sánchez (2011, p. 3) “... las tecnologías influyen en la forma como la juventud piensa y se comporta, creando un camino de dos vías: el comportamiento y puntos de vista de los jóvenes que también influyen y moldean a las TIC”.

A día de hoy, son más de mil setecientos alumnos de los grados de Comunicación Audiovisual y de Publicidad y Relaciones Públicas de la Facultad de Ciencias de la Comunicación de la Universidad de Málaga los que han respondido al cuestionario, durante los últimos cinco años, de 2012 a 2016, desvelando una interesante cantidad de datos que contradicen en diversos aspectos la creencia común de que los jóvenes saben utilizar la Red mejor que sus predecesores, también conocidos como "turistas o inmigrantes digitales"; pero en el presente texto, y para este monográfico, la atención se circunscribe esencialmente a aquellas cuestiones que tienen que ver con los dispositivos y herramientas móviles, es decir, centrando la atención en el uso en este grupo, tanto ordenadores de portátiles, "netbooks", tabletas, teléfonos inteligentes, así como de un buen número de servicios de la Web 2.0 utilizados a través de estos dispositivos.

Por tanto, la presente pesquisa tiene que ver, por una parte, con un análisis diacrónico del fenómeno, en tanto en cuanto se estudian las herramientas que se han venido utilizando en el transcurrir de los últimos cinco años, pero al mismo tiempo es una investigación de los individuos, dado que los 
mismos grupos de estudiantes, que no necesariamente los mismos individuos, repiten la encuesta en años posteriores.

\section{Metodología}

El presente es un estudio cuantitativo, realizado mediante el sistema de encuesta longitudinal, en el que estudiantes de grado son sometidos al mismo cuestionario, al menos en dos ocasiones distintas a lo largo de su paso por la universidad. En la mayoría de casos, dicha encuesta se les ha realizado en primer y tercer curso de grado.

El objetivo de la exploración es conocer el equipamiento técnico que usan los estudiantes para su conexión a la Red y, en el caso de dispositivos móviles, se profundiza en aspectos como el tipo de servicio con que cuentan, para saber qué posibilidades de conexión manejan, dadas las diferencias que puede suponer el acceso a través de una tarifa móvil de prepago o de contrato. Por otro lado, se indaga en las herramientas 2.0 de Internet que conocen, desde el correo electrónico hasta redes más actuales y de contenidos efímeros, como Twitter.

El cuestionario consta de un total de cuarenta y seis preguntas sobre el uso de herramientas 2.0, tanto de elección múltiple como dicotómica, si bien en esta ocasión se oferta la atención, de manera preferente, a las preguntas que tienen relación con los dispositivos móviles y a aquellas otras que, aun no siendo estrictamente referidas a tecnologías móviles, suponen un complemento imprescindible como consecuencia de su valor de operatividad sobre estas herramientas y que van construyendo el rastro, la huella digital de los sujetos a través de sus dispositivos móviles.

Los estudiantes acceden ahora a la universidad con un conocimiento previo de diversos dispositivos electrónicos, "poseen al mismo tiempo percepciones y experiencias diferentes, tienen lógicas de pensamiento distinta y llevan consigo novedosas formas de aprendizaje, de lectura, de creación del conocimiento, de trabajo, así como peculiares prácticas o formas de vivir su cotidianeidad escolar" (Druetta et al., 2011).

Y por ello, parece oportuno que la muestra de población encuestada esté conformada por estudiantes universitarios, concretamente del grado de Comunicación Audiovisual, así como del de Publicidad y Relaciones Públicas, de la Facultad de Ciencias de la Comunicación de la Universidad de Málaga, nacidos principalmente entre 1990 y 1995. Si bien se ha de tener en cuenta que, dada la movilidad nacional e internacional de los estudiantes, resultaría muy difícil intentar realizar la encuesta exactamente a los mismos individuos, sí se puede afirmar que se realiza a los mismos grupos de alumnos.

El aspecto cuantitativo, asentado en los datos extraídos de las encuestas, se ha visto complementado en lo cualitativo por las discusiones en aula sobre las diversas herramientas estudiadas, y por las entrevistas semiestructuradas que a lo largo de estos años se han llevado a cabo con los estudiantes, para que en un entorno informal describiesen sus usos y costumbres en redes sociales.

\section{Resultados}

Para este apartado resulta operativo distinguir entre el "hardware" y el "software" o lo que es lo mismo, entre los dispositivos electrónicos utilizados y los programas o herramientas que conocen y utilizan con los mismos.

En el panorama actual, la inmensa mayoría de aplicaciones están disponibles para los sistemas móviles con más penetración en el mercado, como son Android e iOS, y también para otros sistemas. Y en caso de no existir la "app", siempre podría usarse vía navegador web, por lo que no puede haber 
una relación de exclusión entre el sistema operativo y las herramientas utilizadas. Los jóvenes acceden a las mismas herramientas, independiente del dispositivo o sistema operativo que utilicen para ello.

Los estudios de mercado (Milanesi, 2015) indican que el sistema operativo predominante en España, en dispositivos móviles, es Android (Google), muy por encima de iOS (Apple) y de Windows (Microsoft), y veremos cómo eso mismo se refleja en la muestra observada.

Gráfico 1. Cuota de mercado según sistema operativo en España (\%).

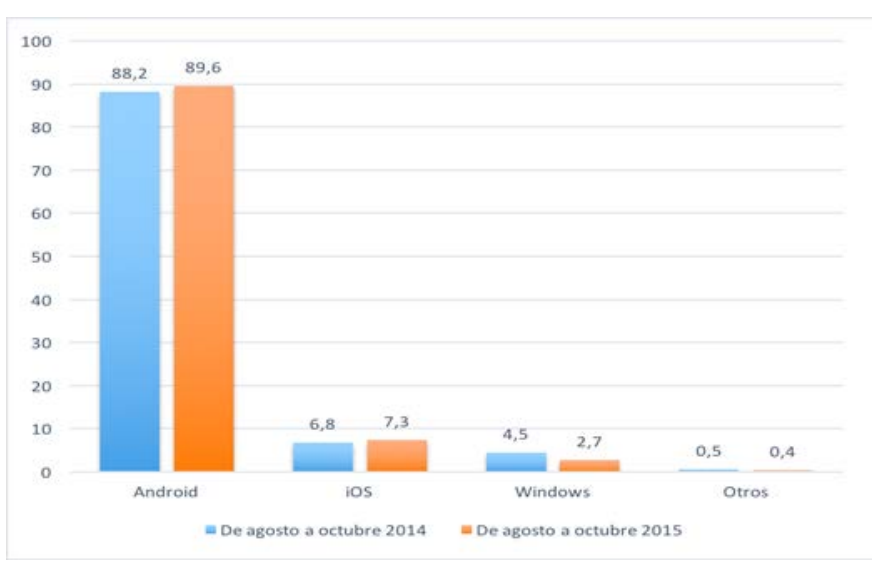

Fuente: Kantar España.

Por otro lado, y antes de adentrarnos en los dispositivos y herramientas utilizados, cabe mencionar el hecho de que hay una leve diferencia en la distribución por género de los estudiantes encuestados con respecto al total de la población española. Así, se puede observar que, según datos del Instituto Nacional de Estadística (2016), apenas existe diferencia en la distribución de la población, con menos de un uno por ciento de variación entre géneros para los mismos períodos recogidos en nuestra encuesta.

Gráfico 2. Distribución por género de la población española.

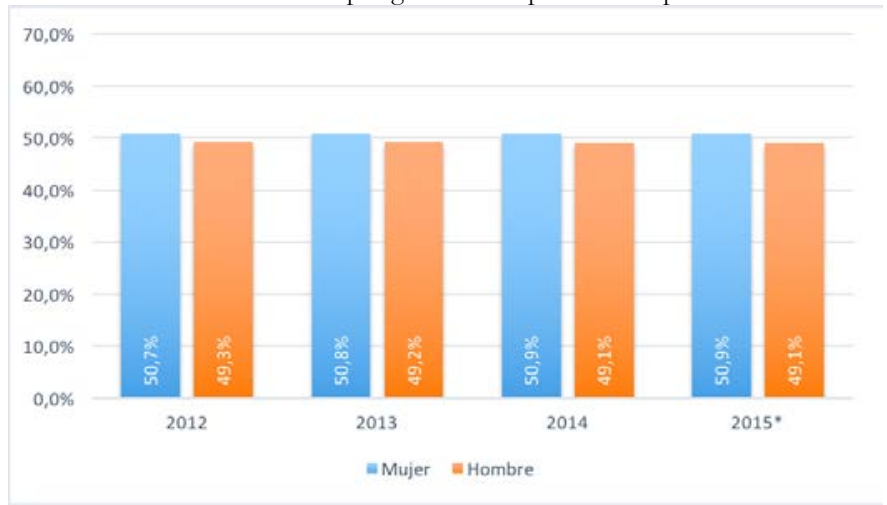

Fuente: Instituto Nacional de Estadística.

Sin embargo, el conjunto de sujetos de la muestra analizada está compuesto por estudiantes de dos grados pertenecientes a la rama de ciencias sociales, ámbito en el que tradicionalmente hay una (C) 
mayor presencia femenina y, aunque esta diferencia pueda resultar significativa en términos absolutos, es recomendable no atribuirle más valor que el informativo, en tanto en cuanto no se ha discriminado el uso de dispositivos y/o herramientas en base al género.

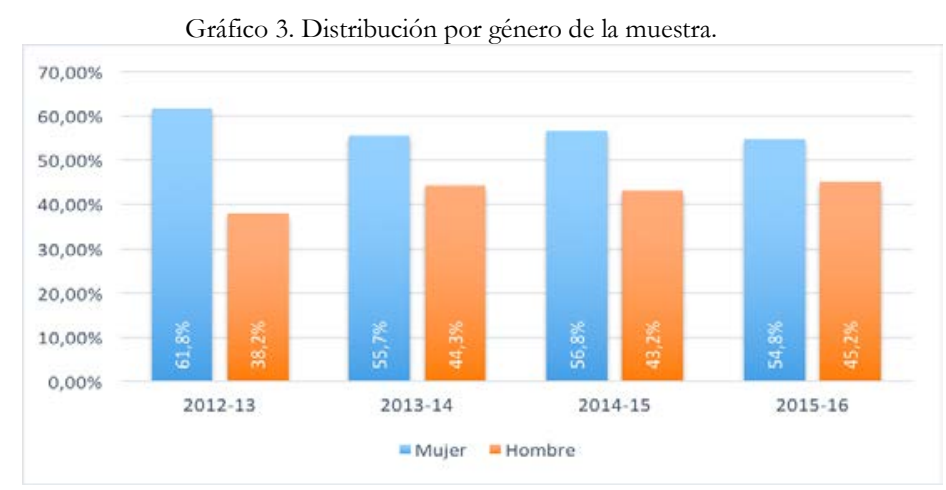

Fuente: Elaboración propia.

\subsection{LOS DISPOSITIVOS}

Al comenzar con el estudio de los dispositivos que los sujetos encuestados utilizan cada día en su ámbito personal y académico, se puede observar que hay un claro predominio tanto del ordenador portátil como del ordenador de sobremesa, que se mantienen en cifras muy similares, si bien se percibe que en este ultimo curso académico ha experimentado un crecimiento negativo leve.

Por otro lado se lee de forma nítida como apenas ha habido incidencia del netbook e incluso menor de la PDA, dispositivo que por edad ya les ha resultado obsoleto.

Sin embargo, resulta llamativo que la tableta tiene aún una penetración muy baja, sobre todo si la comparamos con la del smartphone, que duplica e incluso triplica la penetración en los distintos períodos estudiados.

Se ha de tomar en consideración que la tableta es un dispositivo más propicio para el usuario que quiere recibir y consumir contenidos, y esto también es aplicable a los estudiantes universitarios:

Como en muchos otros aspectos de la vida, los usuarios (estudiantes universitarios en este caso) deciden por un lado para qué quieren usar determinadas herramientas $\mathrm{y}$, por otro, qué necesidades necesitan cubrir con las mismas. Así vemos cómo en vez de utilizar los foros de conversación que las universidades ponen a su disposición a través de sus respectivos campus virtuales, prefieren crear grupos en redes de terceros como Facebook. La explicación es bien sencilla: lo tienen más a mano, lo llevan en sus móviles. Y éste se está convirtiendo en un factor esencial: la movilidad. Cada vez es más habitual ver a los alumnos en clase con tabletas en vez de portátiles, lo que no es malo en sí, pero puede ser poco práctico ya que las tabletas están más optimizadas para leer y recibir contenido que no tanto para generarlo. (Blanco, 2014). 
Gráfico 4. Tipo de dispositivo informático.

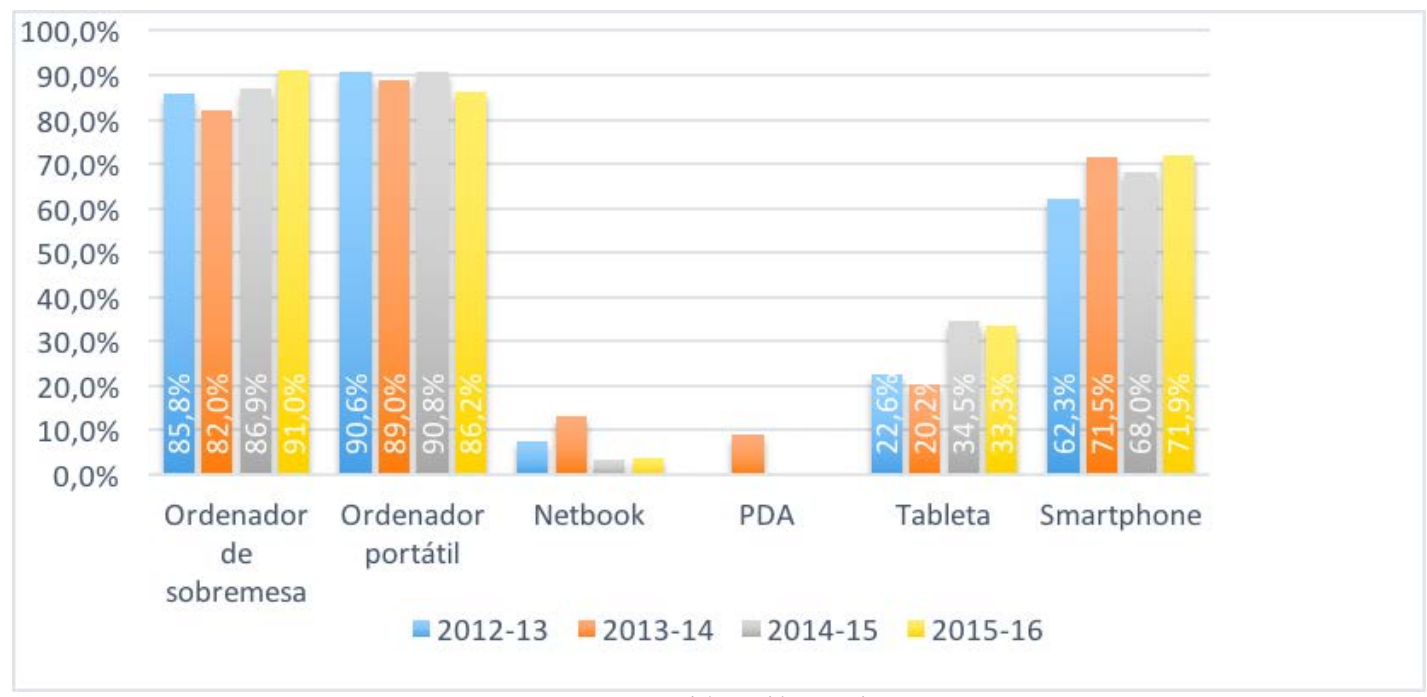

Fuente: Elaboración propia.

Los datos recogidos revelan que los alumnos prefieren el ordenador portátil a la tableta. Y es lógico, dado que el ordenador, ya sea portátil o de sobremesa, es más adecuado para el usuario que necesita generar contenidos. De ahí que estas cifras de penetración se adecuen perfectamente a las necesidades de los estudiantes en plena actividad académica. Pero resultaría interesarte, para futuros estudios, indagar, de forma más concreta, sobre quienes han sustituido la tableta por el ordenador de sobremesa o el portátil.

También es preciso tener en cuenta que la tableta se ha adentrado en los hogares españoles casi como un electrodoméstico más, y no tanto con un uso exclusivo de cada usuario, como claramente sucede con el smartphone. De ahí que fuese de interés discernir si el uso de la tableta era exclusivo o compartido con otros, y en ese sentido, los resultados son los siguientes:

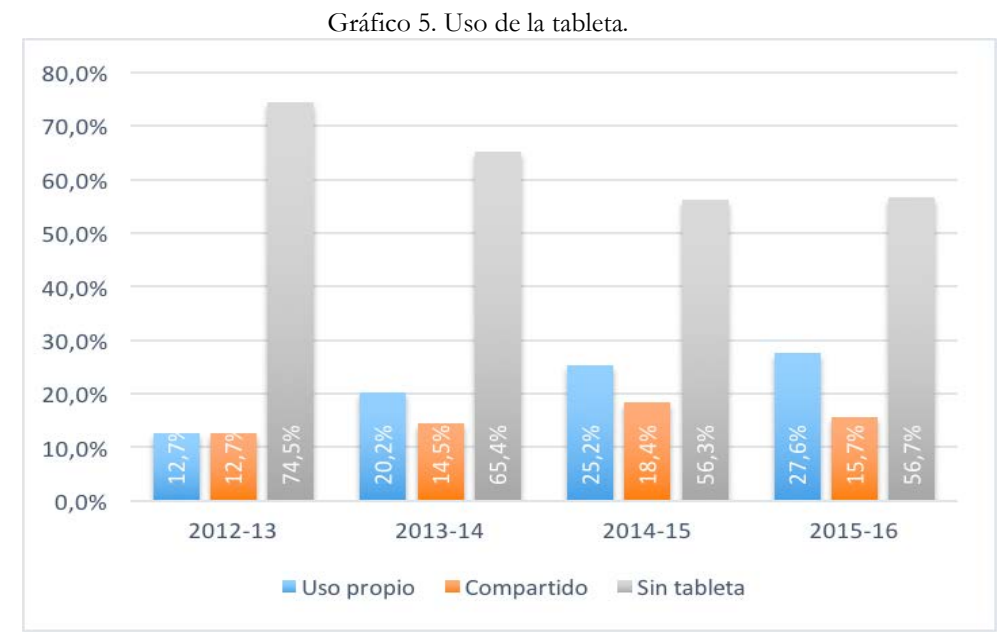

Fuente: Elaboración propia. 
Los estudiantes universitarios tienen unas jornadas que se podrían equiparar a las laborales y, en muchas ocasiones, han de desplazarse a sus centros de estudio durante toda la semana, por lo que se puede ver cómo en el transcurso de los años hay un claro aumento del uso propio y exclusivo del dispositivo, que se sitúa por encima del doble desde el principio de la observación hasta la actualidad, a la par que, lógicamente, disminuye el uso compartido. Así mismo, a pesar de la escasa penetración de la tableta entre los estudiantes, la cantidad de ellos que no disponen del dispositivo ha descendido en 18 puntos porcentuales.

Por lo que respecta al uso de smartphone, se marca una tendencia clara. España es el país europeo con mayor penetración de estos dispositivos entre la población, concretamente un 81 por ciento del parque de móviles son inteligentes (Neira, 2016, p. 20). Pero entre nuestros "millennials" esas cifras son muy superiores. Se ha pasado del 85 por ciento de estudiantes con móvil a casi el 100 por cien $(99,52)$ en estos cuatro períodos académicos, lo que ha provocado una tendencia proporcionalmente inversa en los estudiantes que aún no disponen de dispositivo móvil con conexión a Internet.

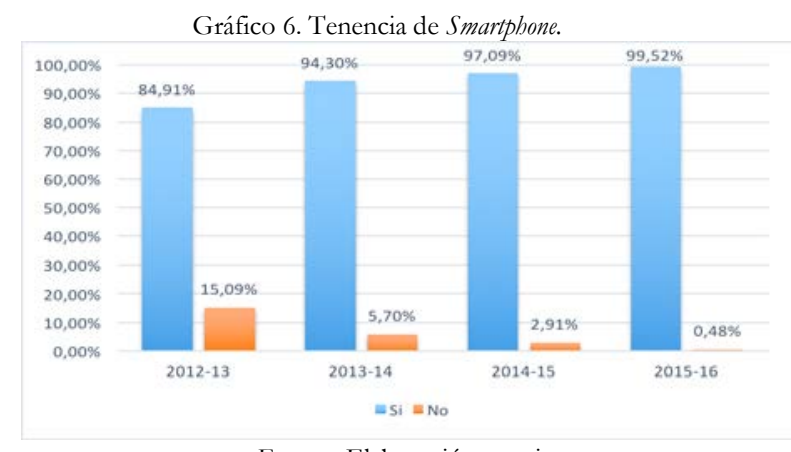

Fuente: Elaboración propia.

Atendiendo al sistema operativo de los terminales móviles vemos que Android tiene un claro dominio sobre el grupo de estudio, seguido a gran distancia por iOS, y aún a más distancia por los sistemas de Blackberry, Windows Phone y un grupo de sistemas agrupados bajo la denominación de “otros", que incluye Symbian, Linux embebido, WebOs, Baada, Meego, Java ME o Windows CE, que pese a ello no supone una cifra significativa.

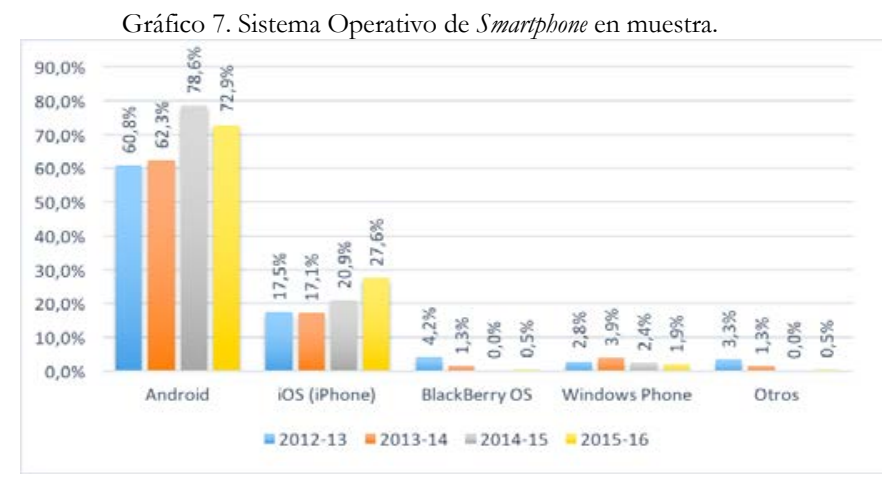

Fuente: Elaboración propia. 
Se pueden comparar estos datos con la tasa de penetración de los sistemas operativos para smartphone en España durante el 2014 y 2015 que proporciona Statista (2016), y se constata que la tendencia es muy similar. Y si bien este estudio no incluye el sistema de Blackberry, resulta de sumo interés tenerlo en cuenta, porque algunas compañías operadoras de telefonía hicieron una importante campaña entre la comunidad universitaria, promocionando estos terminales como modo de introducir a esta generación en el uso de los teléfonos inteligentes.

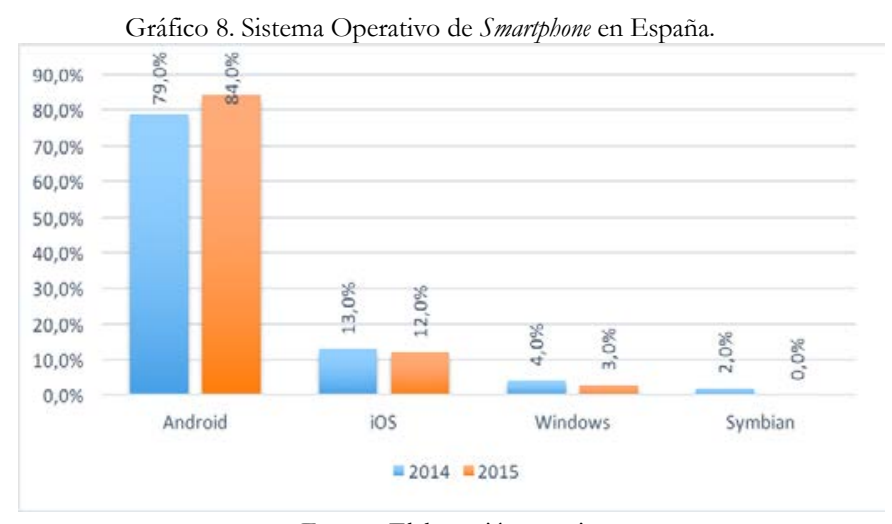

Fuente: Elaboración propia.

Pero también vemos que concide con los recientes resultados de la "18 $8^{a}$ Encuesta AIMC a Usuarios de Internet” (2016), cuyos resultados muestran que Android e iOS son nuevamente los sistemas mayoritarios, con porcentajes del 73 y 26 por ciento respectivamente, y en este informe sí incluyen el sistema de Blackberry, con los mismos resultados que en el estudio que aquí se expone, el 0,5 por ciento.

En la interacción del usuario con las redes sociales y, en general, con todo lo que conlleve su conexión a Internet, tiene una gran importancia el tipo de tarifa de datos de la que disponga el usuario, dado que se entiende que hará un uso más intensivo del dispositivo en la medida en que disponga de un servicio que le imponga menos restricciones a la hora de tener que controlar su tráfico mensual.

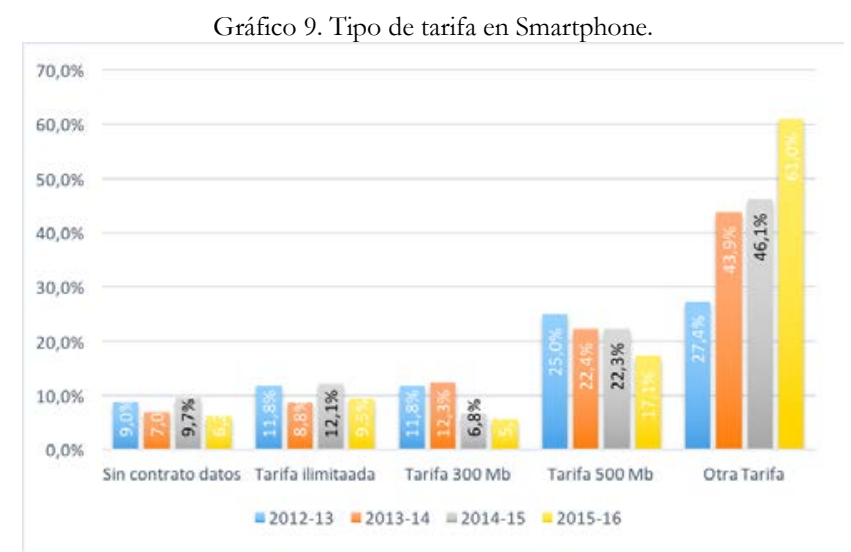

Fuente: Elaboración propia. 
Queda patente cómo las opciones más populares son aquellas que permiten una mayor conectivi$\mathrm{dad}$, como es la tarifa ilimitada en llamadas con $500 \mathrm{Mb}$ de datos, aunque el grueso se decanta por otra tarifa, y ahí se pueden encontrar tipologías tan variadas como 1.000 Mb más 50 minutos de llamadas al mes, o 1.500 Mb más 200 minutos de llamadas.

La penetración de los móviles ha sido tan notable que se ha convertido en el equipo favorito de esta generación para conectarse habitualmente a sus redes sociales, llegando casi a doblarse su uso en los últimos cuatro cursos académicos. Este dato confirma, sin duda, la tesis de que para este grupo etario estar conectado es esencial (Oblinger, 2003, p. 40). Y en este sentido resulta llamativo que, mientras que el ordenador de sobremesa se mantiene en un nivel de uso constante y estable durante el conjunto del periodo estudiado, la utilización del portátil para conectar a redes sociales desciende paulatinamente hasta menos de la mitad.

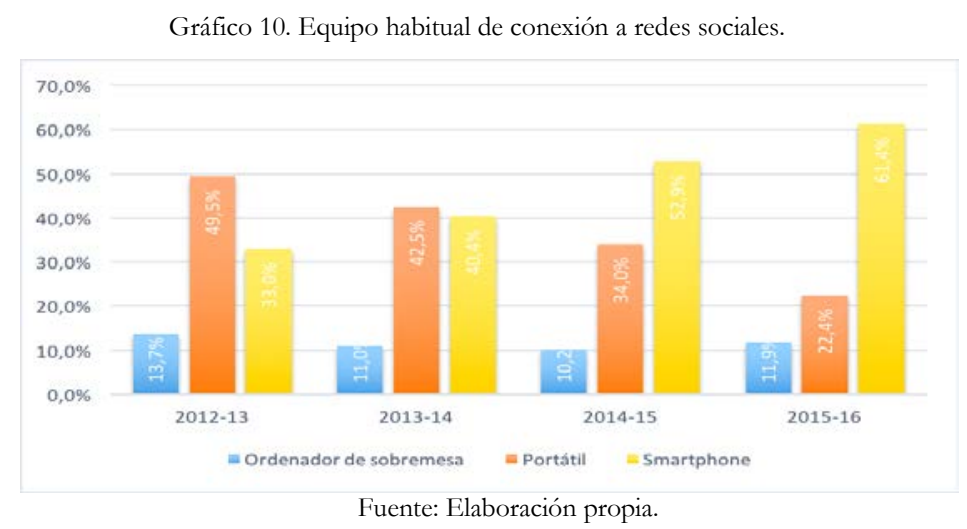

Como conclusión parcial, se puede señalar que los resultados muestran una tendencia clara al incremento en la penetración y utilización de dispositivos móviles, con el smartphone como clara herramienta con vocación expansiva y global, si bien la tableta va ganando adeptos, poco a poco.

\subsection{LOS SERVICIOS 2.0}

En primer lugar cabe centrarse en los servicios Web 2.0 más conocidos entre los usuarios españoles. Se han de incluir aquí redes sociales como Twitter, Facebook o Tuenti, pero también redes profesionales como LinkedIn o Xing.

A nivel general y a lo largo del periodo contemplado, Facebook es la red que más usuarios aglutina, si bien el año pasado sufrió un apreciable descenso, en coincidencia con un claro repunte de Twitter, que acumuló más usuarios. Sin embargo, tal tendencia parece que se manifiesta como fenómeno temporal ya que, durante el último periodo, la red de Mark Zuckerberg ha vuelto a conquistar a los jóvenes estudiantes, mientras que Twitter se ha mantenido estable.

Por su parte, LinkedIn experimentó una subida durante el curso 2013-14, coincidiendo con los años más duros de la crisis económica. Pero en la actualidad ha vuelto a descender, lo que tal vez tenga que ver con el hecho de que los estudiantes, en la situación actual, más que salir y buscar trabajo se plantean continuar con su formación en posgrado, motivo por el que su inversión en currículum 2.0, como resulta ser el uso y mantenimiento de su perfil en LinkedIn, no parece ser una prioridad perentoria. Pinterest sigue siendo una red que no termina de despegar en España, ni siquiera entre 
estudiantes fuertemente vinculados a la imagen. E incluso peor es el dato de Xing, que prácticamente ha desaparecido. En cuanto a la caída de Tuenti, se abordará más adelante, especialmente por la circunstancia de la discontinuidad de su servicio durante el presente año.

Gráfico 11. Redes sociales.

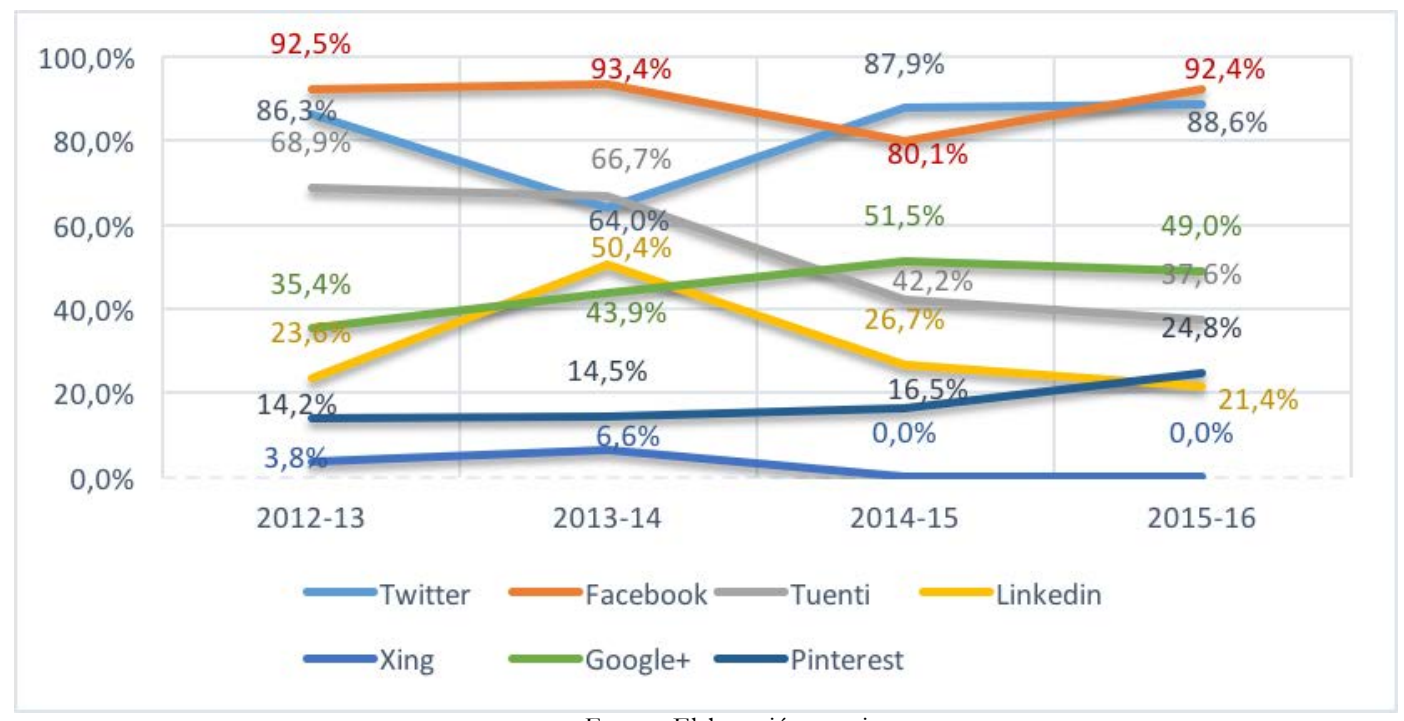

Fuente: Elaboración propia.

El informe de Interactive Advertising Bureau toca también el mismo aspecto de distribución de interés y uso de estas herramientas, en su investigación anual de Redes Sociales (2015), que en su sexta edición, correspondiente a 2014, muestra unos datos que ya empiezan a apuntar la posibilidad de que tal vez los EmillennialsE no son tan tecnoletrados como cabía esperar, ya que en este año Facebook fue la red más usada por los españoles, con un 96 por ciento de ellos, que sin embargo difiere en casi dieciséis puntos porcentuales respecto a lo declarado por los estudiantes encuestados, entre los que su uso se queda en un 81,1 por ciento. Por el contrario, Twitter, a pesar de haber subido siete puntos porcentuales con respecto al año 2013, solo tiene una penetración del 56 por ciento, mientras que en el caso de los discentes universitarios que contestaron el sondeo es casi del 88 por ciento. El uso de Google+ sí es significativamente superior entre estos últimos, con más de quince puntos de diferencia. Pero se puede comprobar que LinkedIn, aun teniendo en cuenta lo anteriormente expuesto, alcanza una penetración inferior en diez puntos porcentuales con respecto al total de la población española. Además, esta red social, asociada a lo profesional, ha subido nueve puntos con respecto a 2013, lo que demuestra la preocupación de la población por la mejora de sus condiciones laborales.

En un reciente estudio publicado The Cocktail Analysis y ArenaMedia (2016) sobre los "millennials" y las redes sociales, también vemos que Facebook es la red más secundada y frecuentada (85\%) seguida de Twitter, con una cifra sensiblemente inferior a la que arrojan los datos del cuestionario $(56 \%)$. También apreciamos una diferencia signicativa con respecto a LinkedIn, de casi once puntos porcentuales, pero hemos de tener en cuenta que la muestra de este informe apenas supera las 400 personas, y además cubre una franja de edad mucho más amplia que la aportada en este estudio, en concreto, abarca de los 18 a los 30 años. 
Otro aspecto fundamental a la hora de tener una amplia perspectiva sobre los usos de los estudiantes en su desenvolvimiento dentro de la sociedad del conocimiento es, sin duda, el dato del tiempo que invierten diariamente en el uso de Internet. Y, como era de esperar, el crecimiento ha sido considerable y continuo a lo largo de estos cuatro períodos académicos.

Gráfico 12. Tiempo diario en Internet.

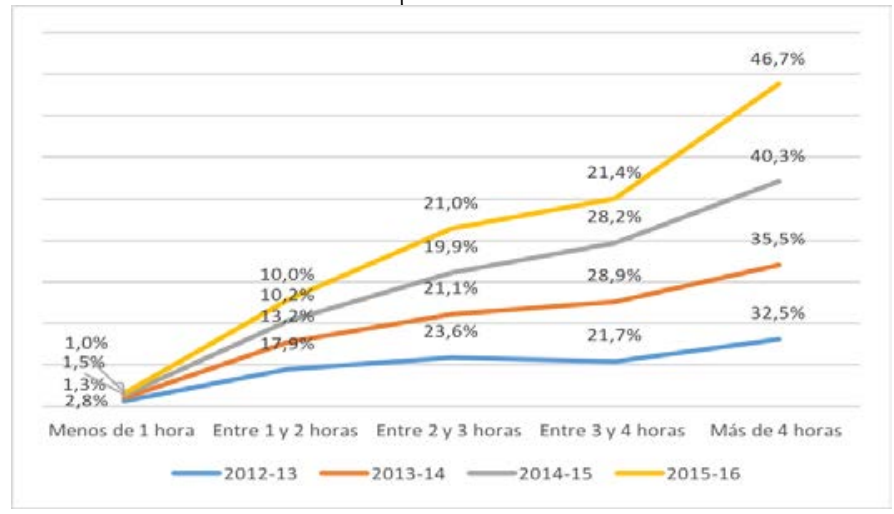

Fuente: Elaboración propia.

En la franja de más de cuatro horas, el incremento ha ido del 32,5 por ciento hasta el 46,7 por ciento, que junto con el 21,4 de aquellos que dedican entre tres y cuatro horas, supone un total de 68,7 por ciento, es decir, más de dos tercios de estos "millennials" universitarios emplean diariamente más de 180 minutos navegando en Internet.

Pero ¿cuánto de este tiempo tiempo pasan los estudiantes en las redes sociales? El lugar común apunta a suponer que pasan demasiado tiempo en ellas, y en el caso de entre un 15 y un 20 por ciento es así, ya que admiten usar más de tres horas al día estos servicios, aunque el grueso de la muestra se sitúa entre una y dos horas. Mucho menos tiempo del que dedican los españoles a ver la televisión, 238 minutos, casi cuatro horas, según los datos del Estudio General de Medios (AIMC, 2015).

Gráfico 13. Tiempo en Redes Sociales.

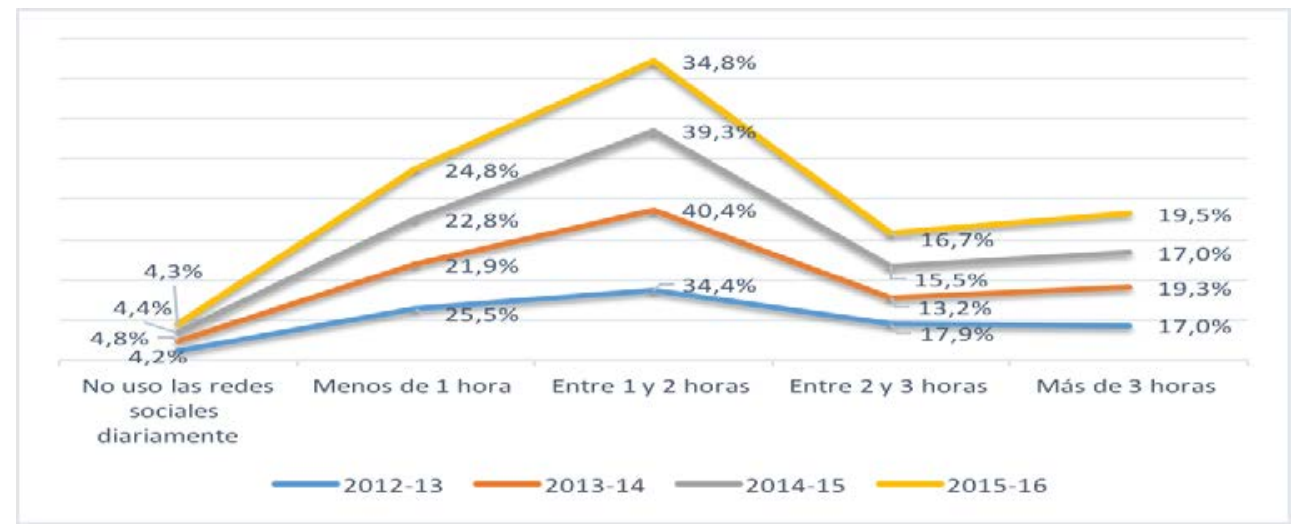

Fuente: Elaboración propia. 
Por otra parte, al examinar con más detalle el manejo de Twitter, se advierte que se trata de una red perfectamente consolidada en el seno de esta generación, con una cifra de penetración que supera el 85 por ciento durante todo el período estudiado, y con más de treinta puntos de diferencia sobre la población general que estudia el IAB.

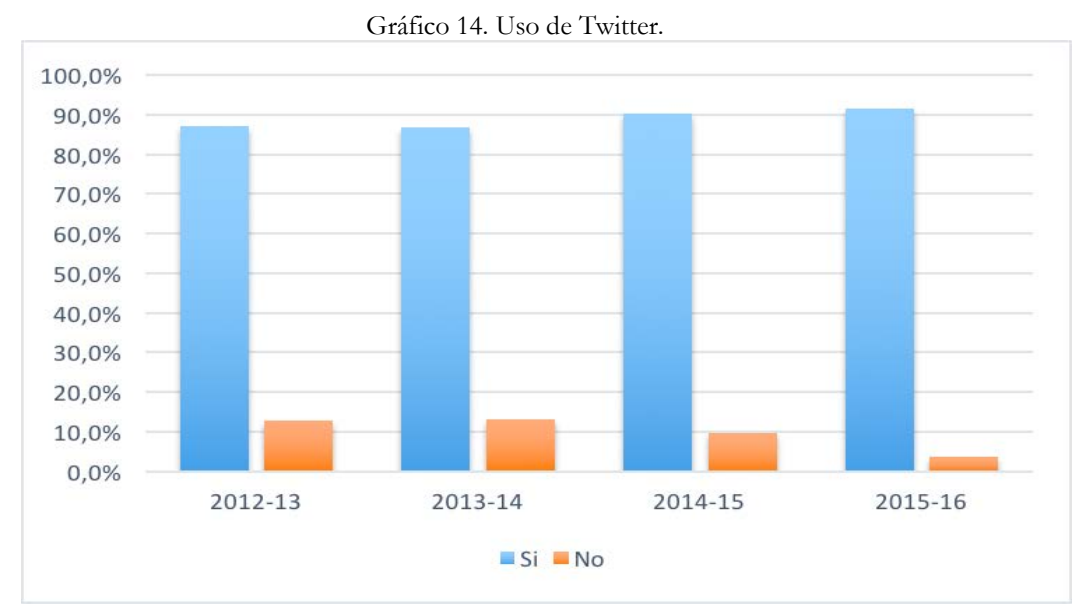

Fuente: Elaboración propia.

Dado este índice de penetración, también se tomó en consideración tratar de discernir los usos habituales en los que se emplea esta herramienta social, y los resultados permiten constatar que la motivación principal para emplearla es el contacto con amigos y conocidos. Sin embargo, al mismo tiempo da soporte al conocimiento de nuevas amistades, así como para establecer contactos profesionales. La creación de una identidad digital profesional, o dicho de otro modo, de la marca personal, no parece preocupar a más del 10 por ciento, en otro claro ejemplo de cómo se están desaprovechando las oportunidades que brinda el 2.0 de cara a una futura inserción en el mercado laboral.

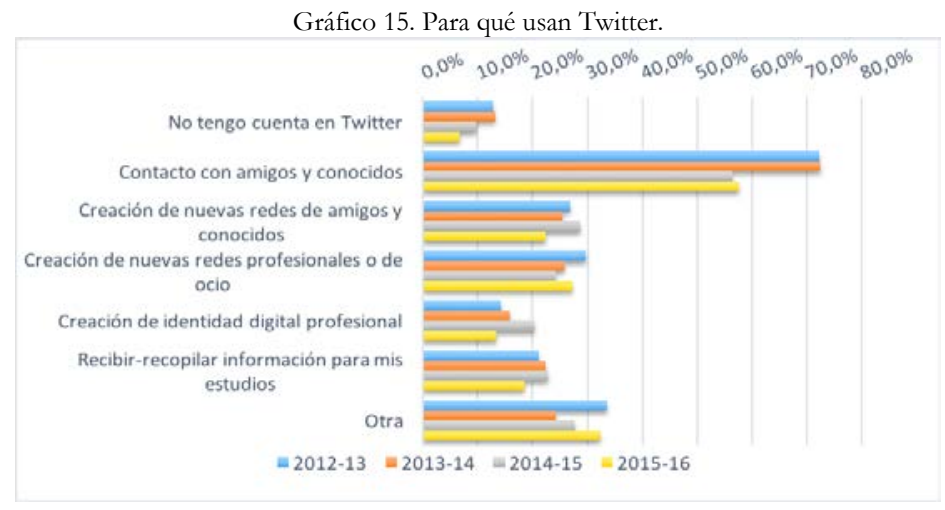

Fuente: Elaboración propia.

Con respecto a las razones para usar las redes sociales en general, de nuevo destaca la motivación de permanecer en contacto con amigos, como primera opción, pero también con la familia, los compañeros de estudios y trabajo, tanto los más cercanos como aquellos que están fuera. Obtiene una 
buena respuesta el hecho de la inmediatez en la comunicación, lo que induce también a compartir fotos con profusión. Pero igualmente se usan para buscar contenidos, tanto de fotos y vídeo como de temas concretos que puedan interesar en cada momento.

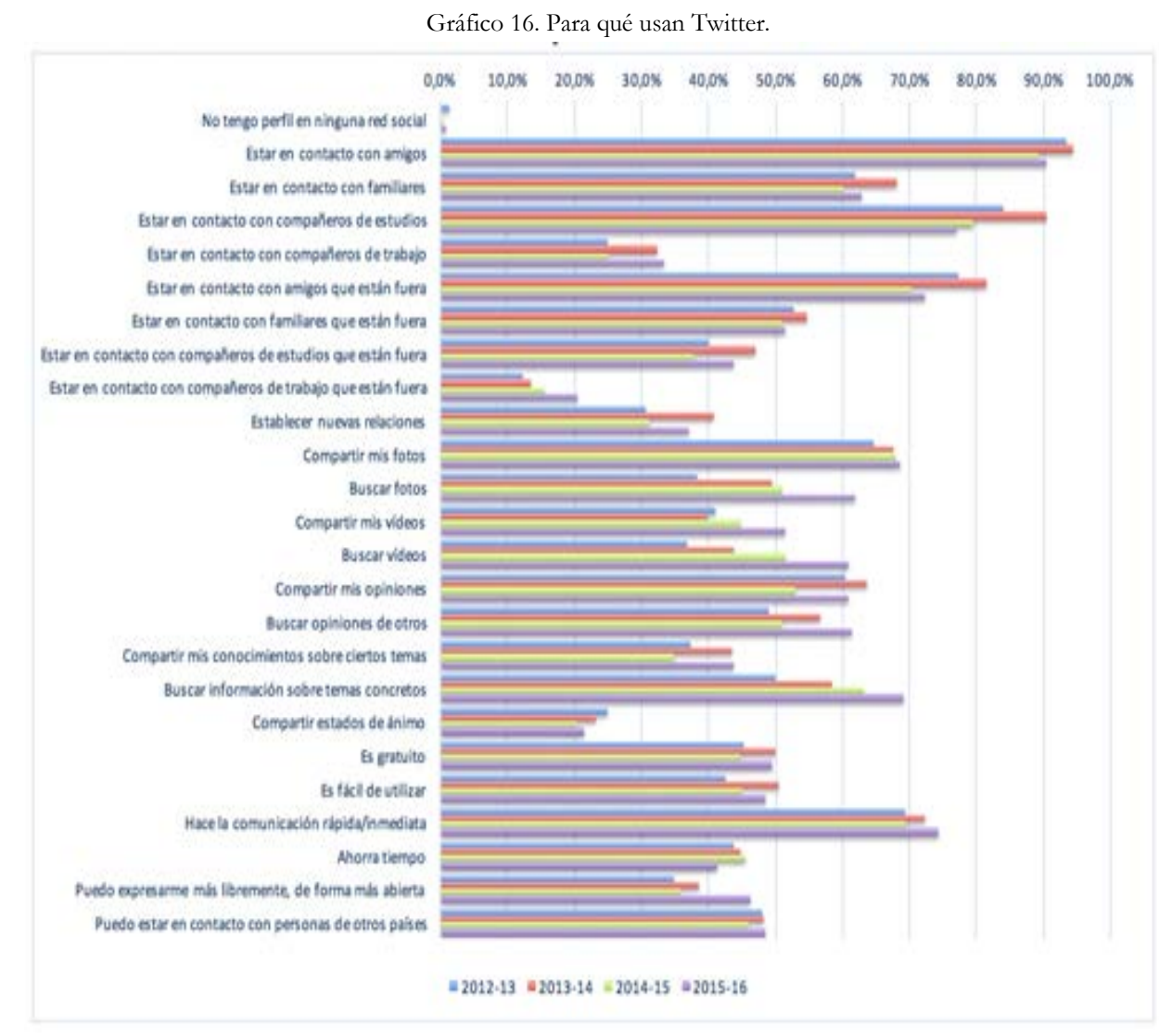

Fuente: Elaboración propia.

Tampoco es despreciable la cifra de estudiantes, un 46 por ciento, que en este año 2015 ve las redes como un sitio donde poder expresarse con libertad y de forma más abierta.

Queda este pequeño comentario sobre Tuenti para el final, ya que fue una de las primeras y más conocidas redes entre los jóvenes, que a medida que iban creciendo se iban incorporando a otras más generalistas como Facebook y Twitter.

Se da la circunstancia además de que Tuenti cierra su servicio este año (Muñoz, 2016), lo que resulta congruente con los datos reflejados en la correspondiente gráfica de descenso de usuarios, y más si se toma en consideración que la gran mayoría de los discentes encuestados, o bien no tienen cuenta en Tuenti o llevan más de un año sin usarla. La representación gráfica de su evolución resulta elocuente.

Como conclusión parcial, se puede apuntar el hecho de que las redes sociales que conocen y con las que están en contacto más permanente, son las más extendidas, pero además, es preciso apuntar que aún siguen usándolas más en el ámbito de ocio y relación personal, y no tanto de cara a su desarrollo profesional. 


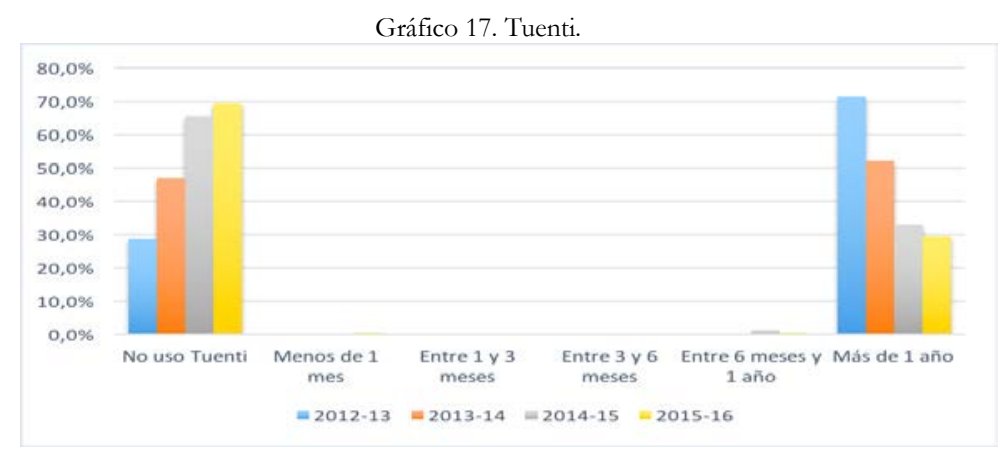

Fuente: Elaboración propia.

\subsection{LOS CONTENIDOS}

Mención especial merecen los contenidos, en tanto en cuanto se puede entender que esta generación, como "nativa digital", tiene un concepto de la privacidad distinto al que tenían sus padres. Están acostumbrados a ir dejando rastro de su presencia en la Red y, como comenta Palfrey Gesser (2008, p. 7), en el mejor de los casos esto implica que muestren lo que quieren ser o que dejan evidencias de su creatividad, pero también es preciso tener en cuenta que, en el peor de los casos, los jóvenes van cediendo información que puede ponerles en peligro, o que sacada de contexto podría humillarles e incluso perjudicarles profesionalmente en el futuro.

En cualquier caso, aun sin profundizar en preguntas que pudieran ser consideradas como intromisión en la intimidad, resulta relevante averiguar si, a través de esa puesta en común de contenidos, se ha podido experimentar algún tipo de problema de reputación profesional en la Red, ya que a través de una observación general, así como en el trato cotidiano en diversas asignaturas, se podía intuir un cierto cambio de tendencia en los últimos tiempos. En un principio los jóvenes se decantaban más por consumir contenidos que por crearlos, por lo que no tenían grandes problemas. Posteriormente se lanzaron a conocer todas estas herramientas y en ocasiones, aunque no en un número significativo, tuvieron incidentes con respecto a su reputación personal, pero con el tiempo parece que la experiencia, propia y ajena, ha movido a cierto grado de reflexión y se han vuelto más prudentes, tanto con el contenido de lo que publican, como en el lugar donde lo hacen, de ahí el aumento de crecimiento de redes como Instagram o Snapchat (Seetharaman, 2015), servicios que ya se han incorporado a la observación este año, aunque no se han incluido, al no ser comparables con datos anteriores.

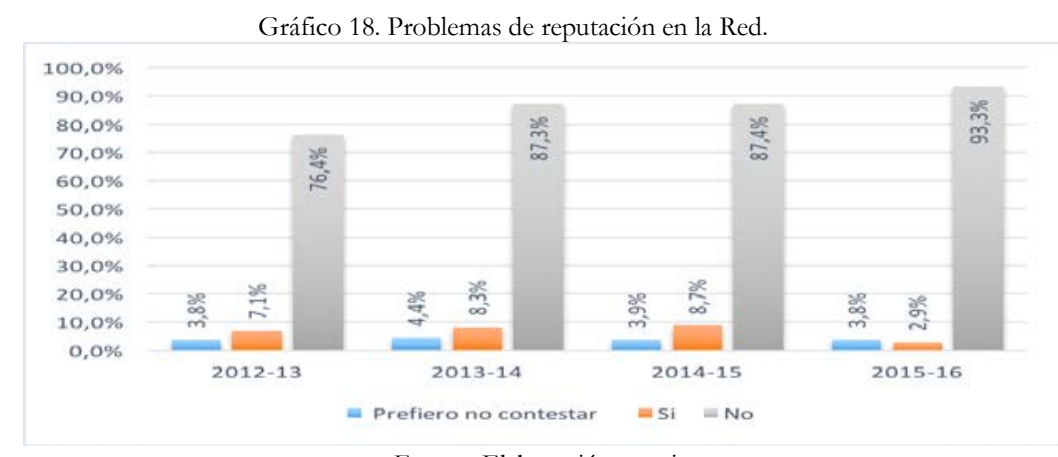

Fuente: Elaboración propia. 


\section{ConClusiones}

Estamos ante una generación permanentemente conectada a través de distintos dispositivos, que van desde el ordenador de sobremesa hasta el smartphone. Un grupo que no entiende su cotidianeidad sin la Red, dado que no han conocido ese escenario, ni contemplan que pudiera producirse.

Por ello, para los jóvenes el smartphone se ha convertido en un dispositivo esencial, hasta el punto de que es su principal vía de acceso a las redes sociales, muy por encima del portátil o del ordenador de sobremesa. Y con estos dispositivos, las tarifas de datos más populares son aquellas que les permiten una mayor conectividad, es decir, aquellas que soportan una mayor cantidad de tráfico de datos, lo que para ellos resulta mucho más importante que la cantidad de minutos de llamadas disponibles. Debemos entender que mientras para la "generación X" existe una diferencia entre la "vida real" y la "vida digital", esta "generación Y" no toma en consideración dicha distinción, en tanto en cuanto ellos nunca los han vivido como dos entornos separados y se mueven entre ambos mundos con natural fluidez.

El tiempo dedicado a Internet, en concreto a las redes sociales, convierte a estos servicios en una especie de compañero virtual que les acompaña cada momento en su día a día, y con el que aprovechan para interactuar en cualquier tiempo y lugar.

El uso principal que hacen de las redes sociales es lúdico-social, en concreto el contacto con amigos y conocidos, y por ello Facebook y Twitter son las herramientas preferidas por estos jóvenes, en concordancia con el carácter más personal que para ellos tiene la Red, aunque han ido abandonando la que en otro momento fue su ágora principal, Tuenti, para adentrarse en aplicaciones más generalistas y no cerradas al exterior. No obstante, y confirmando otra de las hipótesis, se puede apreciar que la actividad de crear redes profesionales tiene una importancia muy inferior a la del uso lúdico de estos servicios, como así lo atestigua la diferencia de 20 puntos porcentuales favorable a este último.

En la misma línea, es reseñable la importancia moderada que conceden a servicios profesionales como LinkedIn o Xing, aunque es previsible que, a medida que se adentren en el mercado laboral, sean estas las herramientas que utilicen en detrimento del currículo tradicional.

Compartir contenidos propios estaría por detrás en importancia, lo que tampoco es de extrañar en un entorno de sobresaturación de "memes" y vídeos virales, que facilitan enormemente la puesta en común de los mismos de una manera expeditiva.

Un dato sorprendente es que estudiantes que han nacido en democracia consideren la Red como un lugar en el que expresarse libremente, lo que sucede con casi la mitad de ellos. De cara a futuros estudios, cabe plantear la búsqueda del tipo de ideas que están dispuestos a expresar en redes sociales pero que sin embargo, por ejemplo, no se atreverían a decir en clase.

Tras la adopción generalizada de estas redes, han pasado de la incontinencia inicial a la hora de compartir sus vidas, a una prudencia que podría estar llegando a ser excesiva, en tanto en cuanto muestran cierta aversión a la hora de mostrar demasiado de sí mismos en las redes, por el perjuicio que podría causarles en su imagen a la hora de encontrar trabajo. Sin embargo, se muestran enormemente receptivos a la hora de aprender todo aquello que les pueda ser útil, tanto en el ámbito personal como académico y/o profesional.

Los "millennials" conforman la primera generación que no ha conocido un mundo sin Internet. Entender esto es labor de sus predecesores, que en el ámbito profesional compete a los reclutadores que se enfrenten a estos candidatos en el futuro, y que deberán comprender que su proceso de aprendizaje ha sido distinto al de generaciones anteriores y que, por tanto, también es diferente su manera de relacionarse e incluso de trabajar. 
Pero antes de llegar al mundo del trabajo, en el ámbito universitario se debe asumir que, en estos momentos, ya no resulta fácil ni apropiado captar su atención, ni enseñarles aquello que pueden encontrar en las redes en pocos minutos. Se trata más bien de dejar a un lado el "qué" se les enseña, para profundizar en el "por qué" y "para qué", así como en el "dónde” encontrar y "quién" ofrece confianza, así como una serie de conocimientos propedéuticos que les prepare para el continuo aprendizaje y actualización que tendrán que afrontar en el futuro.

\section{BibliogRAFÍA}

AIMC. (2015). Estudio General de Medios. Febrero a Noviembre 2015. Resumen General. Asociación para la Investigación en Medios de Comunicación (AIMC). Recuperado a partir de http:/ / www.aimc.es/spip.php?action=acceder document\&arg $=2974 \& \mathrm{cle}=08 \mathrm{efe} 06 \mathrm{e} 64115 \mathrm{e} 7$ 4ee48bd42eafc913eef $981 \mathrm{c} 8 \mathrm{c} \&$ file $=$ pdf $\% 2$ Fresumegm315.pdf

AIMC. (2016). Navegantes en la Red. (Encuesta AIMC a Usuarios de Internet No. 18). Encuesta AIMC a Usuarios de Internet (p 192). Madrid: AIMC - Asociación para la Investigación de Medios de Comunicación. Recuperado a partir de http://download.aimc.es/aimc/ROY76b/macro2015.pdf

Arras Vota, A. M. de G., Torres Gastelú, C. A., y García Valcárcel Muñoz Repiso, A. (2011). Competencias en Tecnologías de Información y Comunicación (TIC) de los estudiantes universitarios. Revista Latina de Comunicación, 66. doi:10.4185/RLCS-66-2011-927-130-152

Blanco, S. (2014, julio 29). Nativos digitales y tecnoanalfabetos funcionales. Cibersur.com. Recuperado septiembre 24, 2014, a partir de http://www.cibersur.com/016018/nativos/digitales/tecnoanalfabetos/funcionales

Cervera, M. G., Vidal, C. E., y Martínez, J. G. (2011). Cómo trabajar la competencia digital con estudiantes universitarios. La práctica educativa en la Sociedad de la Información: Innovación a través de la investigación (pp. 157-174). Editorial Marfil. Recuperado a partir de http://www.edutic.ua.es/wp-content/uploads/2012/06/La-practica-educativa 157 174CAP14.pdf

Comision Europea. (2007). Competencias clave para el aprendizaje permanente. Un marco de referencia europeo. CE. DG Educación y Cultura. Recuperado a partir de http://www.mecd.gob.es/dctm/ministerio/educacion/mecu/movilidadeuropa / competenciasclave.pdf?documentId=0901e $72 \mathrm{~b} 80685 \mathrm{fb} 1$

Druetta, D., Garay Cruz, L., López González, R., y Portillo Sánchez, M. (2011). Uso y apropiación de la telefonía móvil. Opiniones de jóvenes universitarios de la UNAM, la UACM y la UPN. Derecho a Comunicar Magazine. Issue, 3.

EPA de España 2015. (2016). datosmacro.com. Recuperado febrero 22, 2016, a partir de http://www.datosmacro.com/paro-epa/espana

Gallardo Echenique, E. E., Marqués Molías, L., y Bullen, M. (2014). Usos académicos y sociales de las tecnologías digitales del estudiante universitario de primer año. Tendencias pedagógicas, 23, 191204.

Gardner, H., y Davis, K. (profesora). (2014). La generación app: cómo los jóvenes gestionan su identidad, su privacidad y su imaginación en el mundo digital. Barcelona: Paidós. 
Howe, N., y Strauss, W. (2007). The Next 20 Years: How Customers and Workforce Attitudes Will Evolve. Harvard Business Review. Recuperado a partir de https://hbr.org/2007/07/the-next20-years-how-customer-and-workforce-attitudes-will-evolve

Howe, N., y Strauss, W. (2009). Millennials rising: The next great generation. Vintage.

IAB. (2015). VI Estudio Redes Sociales de LAB Spain. IAB. Interactive Advertising Bureau. Recuperado a partir de http://www.iabspain.net/wpcontent/uploads/downloads/2015/01/Estudio Anual Redes Sociales 2015.pdf

INE. (2016). INEbase / Demografía y población / Cifras de población y censos demográficos / Cifras de Población. Instituto Nacional de Estadística. Recuperado febrero 27, 2016, a partir de http://www.ine.es/inebaseDYN/cp30321/cp inicio.htm

Matilla, M., Sayavedra, C., y Alfonso, V. C. (2014). Competencias TIC en alumnos universitarios: Dimensiones y Categorías para su análisis. Memorias del Congreso. Presentado en Congreso Iberoamericano de Ciencia, Tecnología, Innovacion y Educación, Buenos Aires, Argentina: Organización de Estados Iberoamericanos. Recuperado a partir de http://www.oei.es/congreso2014/memoriactei/1534.pdf

Milanesi, C. (2015, diciembre 9). Android vuelve a crecer en Europa impulsado por España e Italia. Kantar. Recuperado febrero 22, 2016, a partir de http://es.kantar.com/tech/móvil/2015/diciembre-2015-cuota-de-mercado-de-smartphonesen-españa-de-agosto-a-octubre-2015/

Millennials y Redes Sociales (No. VII Ola). (2016). Observatorio Redes Sociales. Madrid: The Cocktail Analysis y ArenaMedia. Recuperado a partir de http:/ / tcanalysis.com/blog/posts/millennials-y-redes-sociales-nuevo-proyecto-de-thecocktail-analysis-y-arena

Monfort, A. P. S., y Hurtado, E. P. S. M. (2013). Los códigos lingüísticos de las nuevas tecnologías. X Jornadas de Sociología. Facultad de Ciencias Sociales, Universidad de Buenos Aires. Recuperado a partir de http://www.aacademica.org/000-038/296

Muñoz, R. (2016, febrero 2). Tuenti cerrará gradualmente su red social para centrarse en la telefonía. EL PAÍS. Recuperado febrero 27, 2016, a partir de http://economia.elpais.com/economia/2016/02/01/actualidad/1454341370 798355.html

Neira, E. (2016). La otra pantalla: redes sociales, móviles y la nueva televisión. Barcelona: UOC.

Noguera, J. M., Grandío, M. del M., y Torrado, S. (2011). Competencias digitales para los nuevos entornos dentro de los estudios de grado en Comunicación Audiovisual. Innovación Educativa, 21, 317-327.

Oblinger, D. (2003). Gen-Xers, and Millennials: Understanding the 'New Students'. EDUCAUSE, 38(4). Recuperado a partir de https://net.educause.edu/ir/library/pdf/erm0342.pdf

Palfrey, J. G., y Gasser, U. (2008). Born digital: understanding the first generation of digital natives. New York: Basic Books.

Seetharaman, D. (2015, octubre 16). Survey Finds Teens Prefer Instagram, Twitter, Snapchat for Social Networks. WSJ Blogs - Digits. Recuperado a partir de http://blogs.wsj.com/digits/2015/10/16/survey-finds-teens-prefer-instagram-snapchatamong-social-networks/ 
Statista. (2016). Sistemas operativos smartphone: penetración 2014-2015 | España. Statista. Statista, . Recuperado febrero 27, 2016, a partir de http://es.statista.com/estadisticas/473759/tasapenetracion-sistema-operativo-smartphone-espana/

Tapscott, D. (2009). La era digital: cómo la generación net está transformando al mundo. México: McGraw Hill Interamericana.

Taylor, M. (2005). Generation NeXt: Today's postmodern student-meeting, teaching, and serving. $A$ collection of papers on self-study and institutional improvement, 2(4). Recuperado a partir de http://taylorprograms.com/images/Gen NeXt article HLC 05.pdf

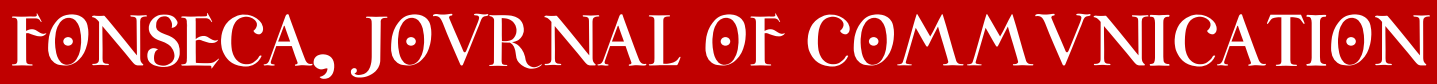

